\title{
The Views of Participants for the Improvements in Science Education Lessons According to the European Union Education Policies
}

\author{
Paşa YALÇIN \\ Erzincan Binali Y1ldırım University \\ Faculty of Education \\ Department of Mathematics and Science Education, Science Education \\ Erzincan 2400, Turkey \\ Esin ZAIM \\ Erzincan Binali Yıldırım University \\ Institute of Natural Sciences, Science Education \\ Erzincan 2400, Turkey \\ Sema ALTUN YALÇIN \\ Erzincan Binali Y1ldırım University \\ Faculty of Education, \\ Department of Mathematics and Science Education \\ Erzincan 2400, Turkey
}

\begin{abstract}
With this present study, the improvements-carried out in the science education in Turkey-were investigated for the first time considering the science education policies of the European Union (EU)The participant views were taken into consideration on the science improvements carried out according to the EU education policies. With this purpose, science teachers, the personnel of the national education in a medium province in the Region of Eastern Anatolia, and administrative personnel were chosen to constitute the universe of the research. Mixed method was applied during the research. A Likert type questionnaire including 10 questions was conducted to the participants to learn their thoughts about the EU science education policies as the quantitative method. In the qualitative method, open-ended questions including 8 items for each were asked to the participants. According to the result of the study, when the collected data were evaluated, it was found out that most of the participants were ignorant of the EU policies, few numbers of the individuals constituting the sampling were informed about these policies; but, they thought that it would be more appropriate to take and implement policies in accordance with our national values. When the qualitative data were evaluated, it was expressed that some improvements were conducted in the science education lessons compared with the previous programs; but, that was insufficient.
\end{abstract}

Keywords: European Union(EU) Education Policies, EU Science Education Policies, Science Education, Science and Technology Lesson, Participant Opinions

\section{Introduction}

The developments in technology and social development of the countries have necessitated to settle several unions and to make solidarity among them. Several unions were settled similar to this union and one of them was the EU. Almost a decade after the World War II, Turkey tried to join the EU and applied to join this union in 1959 first. From the first application year until now, Turkey has taken several steps related to provide conditions to join the EU integration and as a result of this, the negotiations with EU were begun in 2005.The EU was settled to produce coal and steel collaboratively by five countries 60 years ago, within the years, it was developed based on improving cooperation and collaborative policies in economical, social, cultural, law and political fields and with the joining of Bulgaria and Romania in 2007, the number of the members reached 27. Croatia joined to the EU as the 28th member in the second half of 2013. The members of the Union mostly apply the decisions taken by the union in almost every area of life. Member countries are represented in the European Commission and the European Parliament and participate in the decisions. 
The institutions of the union related to the fields of industry, agriculture, environment, education, science and technology, and its projects related to cooperation between these institutions are continuously developed, and the results of the activities are evaluated in the meetings. Thus, Andrew Workink, the Director of Turkey in the World Bank, assessing the point reached in the field of education in Turkey, in the Symposium of Education in Turkey and Private Schools, EU Vision in Antalya in 2006, said: "Turkey is back in pre-school education. In addition, secondary education results in Turkey do not fit the EU. Drawing attention to the various steps taken to advance the education, Turkish school system educates a handful of students well; but, makes the majority of students unsuccessful"'(Workink, 2006).

As the studies in the literature are investigated, it is noticed that some various studies are being carried related to the EU (Lewin,2000; Rees, 2001; Cogan \& McDevitt, 2003; Aslan \& Gökkaya,2004; Gedikoğlu, 2005; Karip,2005; Erginer, 2006;Akpınar, 2006; Gültekin \& Anagün, 2006; Cansever, 2009; Demirbaş, 2010;Eisfeld \& Pal, 2010; Hasdemir and Çalıkoğlu, 2011; Sağlam, Özüdoğru \& Çıray, 2011).

Related to the topic, Akpinar (2006) tried to determine the EU image of the primary school students in"The EU image of Turkish primary school students in the EU integration process" named study. With this purpose, a questionnaire was applied for totally 894 students. The collected data were analysed with the percent, frequency, and chi-square techniques. The findings handled as a result of the study were analysed by grouping them in various sub-problems. According to the analyses of the gathered data, it was found out that the primary school students mostly support Turkey's joining to the EU; but they think that it is almost impossible. The primary school students look positively to live with Europeans and like to be educated in these countries.

Başbay \& Doğan (2004), in their study named as "Teacher views on the effects of the EU membership process on our education system", applied a measure to 367 teachers to take their opinions related to the effects of the EU membership process on our education system, and the results were analysed with the SPSS package program. According to the results of the analysis, it was believed that the EU membership process would have positive effect on our education system and with the help of possible changes that can be occurred; our system might be reached the EU standards.

Aslan \& Gökkaya (2004) tried to determine how the applied general objectives of the social science lesson might be affected after the EU membership in their studies called as: "The effect of the EU education policies on the general objectives of the social sciences lesson". With this purpose, a questionnaire was applied to 257 students and the results were analysed with the SPSS package program. Considering the gathered results, it was found out that while some gains may be affected positively as a result of the EU membership, on the other hand, others may be affected negatively.

Gedikoğlu (2005) handled the problems of Turkish Education system in his study named as "Turkish education system in EU membership process: Problems and solution suggestions" and focused on how to deal with these problems. Claiming that the main problem was not at the single level of education, but lots of problems existed in all the levels to the higher education, it was focused on how to create solutions for these problems.

Erginer (2006) demonstrated the similarities and differences between the Turkish and EU education system comparing the Turkish education system and EU education system in the headings of aim, structure, management and management processes in the study named as: "The EU education systems and comparisons with the Turkish education system". Gültekin \& Anagün (2006) tried to analyse Turkey's situation in terms of the indications determined by the EU related to the education in the study named as: "The situation of the Turkish education system in terms of the decisive areas and indicators of the quality of education in the EU". According to the analysis results, Turkey, as a country trying to join the EU, has to develop the education in terms of the quality and quantity. As the indicators of the EU related to the education were taken into consideration, it was found out that Turkey was behind the other European countries, far from meeting the EU standards, and was also determined that Turkey was below the scores of the EU countries in the international exams as TIMSS and PIRLS. Cansever (2009), in the study named as "EU education policies and assessment of Turkey's alignment with these policies", evaluated the EU membership process in some topics such as: increasing the amount of resources allocated and spent to education for Turkey's Lisbon Strategy, increasing the rate of females in education, Increasing the female population participating in various jobs. Hasdemir \& Çalıkoğlu (2011), in the study named as: "The EU education programs and change" it was observed that Turkey has participated in several programmes since 2004 such as; 
The Lifelong Learning Programme and Youth Programme, and these programmes had positive effects especially on the higher education institutions, the personnel in these institutions and students. Sağlam, Özüdoğru \& Çıray (2011), it was tried to investigate the effects of the policies related to the primary, secondary and higher education on the Turkish education system in their studies named as; "The EU education policies and their effects on the Turkish education system". According to the results of the study, it was determined that Turkey made various changes in the topics of education in the policies in each field.

The first question that can be occurred in the mind is what the strategies related to the science education are. Strategies to support science education are rare and there are eight countries with frameworks for implementing training strategies.

Three fundamental areas pointed in these strategies are observed as; curriculum, teaching methods and teacher education. Most countries associated their science education support strategies with science based instructions and these strategies related to the science education are:

Integrated Science Teaching Strategy; Integrated science teaching mostly occurs in sub-levels of the education. Almost in all the Europe, the science education was taught in an integrated course throughout primary education and generally is continued as in this way in the two years of the secondary education. In Turkey, it is taught between the primary school 4th and secondary school 8th grades under the science education lesson.

More Context Based Science Teaching and Practice Activities Strategy: Researches reveal that teaching students with real life experiences and discussing the social dimensions of science is an important factor in increasing student motivation and science education. It should be aimed to intimidate the students a reflection of the events and situations that the science content in the school actually faced in everyday life. Thus, it should be aimed to develop positive attitudes of the students towards these lessons, increase their academic achievements, decrease their worries, raise their interest, excitement and motivations in the lessons; that is, develop their self-arrangement skills.

Strategy for Assessing the In-class or Educational Process: The methods used to measure the knowledge and skills of the students should reflect and support the objectives and learning outcomes specified in the curriculum. In half of the countries and regions of the Europe, there are already guidelines for measurement and evaluation in science education. These guidelines consist of suggestions to teachers for the types of techniques should be used when measuring their students' achievements.

At Least a Standard Measurement Strategy throughout the Compulsory Education: In most of the European countries and/or regions, measurement based on national standards to measure students' knowledge and skills in science education should be done at least once.

Strategy for Developing Teacher Skills: Countries with a strategy framework to support science education take the education of science education teachers as a measure; yet, national initiatives related to the training of the preservice science education teachers' training are not encountered so frequently (Vassiliou, 2011).Professional renewal programs should be included in order to strengthen the teachers with the modern principles required by the profession, to contribute to their knowledge and skills.

In this present study, teachers, administrative personnel and the staff of the national education directorate in the province were included in the study as the sampling. The reason why the sampling was chosen from this group was that they were the practitioners of the changes and improvements occurred in the science education until now. With the help of this study, it was aimed to find out the answer to the question whether there were improvements in science lessons in Turkey and if there were deficiencies in science lessons in Turkey, which was trying to join the EU, how these deficiencies can be eliminated, considering the policies of the EU science education and the basic strategy supporting the science education

\section{Method}

Research Method: The mixed methods- qualitative and quantitative- were tried to be used together in the study. In the qualitative method, the data were collected with a half-structured protocol by asking 8 open ended questions to the teachers. In quantitative method, the teachers were applied with a likert type questionnaire including 10 questions. 
Research Problem: Do the teachers have ideas about the improvements in science lessons in Turkey considering the EU policies? In order to investigate the research problem in detail, these following sub-problems were conducted. In terms of the participants' knowledge levels about the EU policies;

1. When the science-teaching curriculum is being renewed, what are the views on the case of taking active learning as the base?

2. What are the views of whether the constructivist approach makes the science and technology curriculum useful or not?

3. What are the views on whether the constructivist approach will be effective in teaching science and technology issues?

4. What are the views of science teachers on whether it is effective to establish inter-course relations while teaching them?

5. What are the views on whether it would be useful to use contemporary methods in classroom assessment?

6. What are the views on whether there is a relationship between EU science education policies and science courses taught in Turkey or not?

7. What are the views on whether the curriculum is prepared according to constructivist approach or not?

8. What are the views on the sufficiency of in-service training to increase teacher qualifications?

9. What are the views on whether the science program is more relevant to real life experiences or not compared with the old program?

10. What are the views on whether the topics in the new science program are appropriate for the student level or not?

11. What are your views on EU science education policies?

12. What are the views on improvements in science lessons in Turkey, considering EU policies?

\section{Hypotheses:}

1. It was accepted that the survey materials used in the collection of research data sincerely responded by the participants to reflect the truth.

2. The survey tool used to collect data in the survey was considered to be prepared in the nature of the purpose of the survey.

\section{Limitations: In this research;}

1. It is limited with the schools of the Ministry of Education in Eastern Anatolia Region of Turkey in a province with 100.000 populations in 2015-2016 education years.

2. The data collected in the research are limited with 100 participants including teachers working within the scope of the Ministry of Education, personnel in the provincial national education directorate, and administrative personnel in a province with 100.000 populations in the Eastern Anatolian Region in Turkey.

3. The questionnaire items are limited with 8 open-ended questions used to collect the research data.

Universe and Sampling: Science teachers, the personnel of the national education in a medium province in the Region of Eastern Anatolia, and administrative personnel were chosen to constitute the universe of the research. The sampling of the research consisted of 100 participants who were the teachers in 2015-2016 education year chosen from the research universe with random sampling (Balc1, 2013).

Data Collection Tools: During the research, a likert type questionnaire including 10 items was applied in order to determine the views of teachers whether there were improvements in science lessons in Turkey according to the EU policies. The agreement levels of the participants for each item in the questionnaire were determined as "completely disagree: 1", "disagree: 2", "undecided: 3", "agree: 4" and "completely agree: 5".

During the development stage of the questionnaire, with the help of the resources gathered with reviewing the literature firstly, a pool with 20 items was constituted. After the analysis of the item tool, the items measuring the similar specialities were omitted from the pool and the number of item was decreased to 10. Analysing the item pool, it was tried to make the terms and sentences more simple and understandable. In addition, the items stated in the item pool were analysed by the academicians from the "Department of Science Education", their views were taken and arrangements were made to provide the content validity. The sentences including two or more judgments were shortened in sentences with single sentences according to the advices from the experts, the items, which were thought to be too long and might distract the attention of the readers, were shortened and the items including complex terms were written simpler and necessary arrangements were made. 
Application Processes of the Research: The developed questionnaire and open-ended questions were applied to the sampling thought to represent the universe of the research and research data were collected. In order to avoid possible misconceptions, necessary explanations were made by the researchers to the participants in the data collection in terms of helping to answer the items stated in the questionnaire. In order for the items to be answered in the questionnaire form, the necessary time was given to the individuals in the sampling and the questionnaire was filled. The gathered data were analysed with the statistical programs. With the help of the graphs created on the screen, the research problem was tried to explain.

\section{Findings}

In the research, the findings relevant to the views of the participants about the improvements in science lessons in Turkey according to the EU science education policies are presented according to the sub-problems of the research:

The Views Related to the Taking the Active Learning to the Base during Renewing the Teaching Program; The participants were asked whether the active learning should be taken to the base or not during renewing the science-teaching program in the research and the choice cases of the participants are indicated in Figure 1.

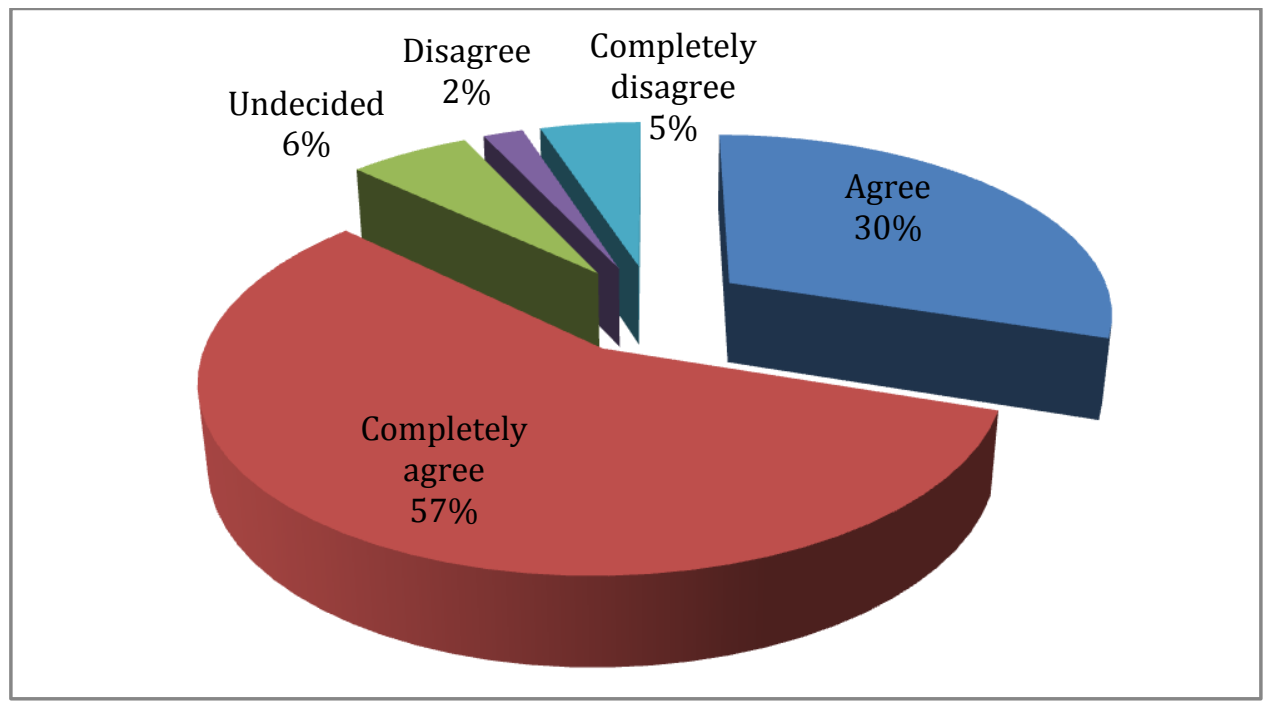

Figure 1.The views of the participants on taking the active learning to the base during renewing the science teaching program.

As the Figure 1 is analysed, it is understood that $57 \%$ of the participants participating to the research thought that the active learning should be taken as the base in renewing the science teaching program, $5 \%$ of them completely disagreed, $2 \%$ of them did not agree, $6 \%$ were undecided, $30 \%$ thought that it was necessary. Considering these findings, the participants think that the active learning should be taken as the base when the science curriculum is being renewed.

Opinions Related to Whether the Constructivist Approach Make Science and Technology Teaching Program Useful or not; The participants were asked whether the constructivist approach made the science and technology curriculum useful in the research and the choices of the participants are shown in Figure 2. 


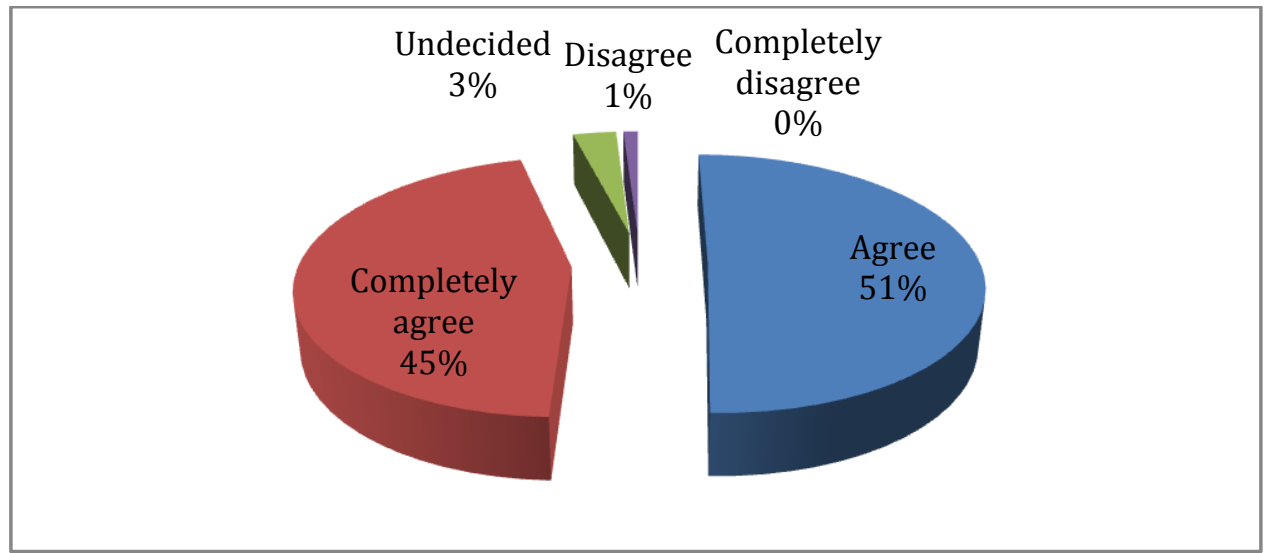

Figure 2. Participants' views whether constructivist approach made the science and technology curriculum useful or not.

As the Figure 2 is investigated, it comes into being that, while $46 \%$ of the participants participated in the research believed that the constructivist approach definitely made the science and technology program useful, $1 \%$ did not agree, $3 \%$ were undecided, $50 \%$ of them believed that it made the curriculum useful. Considering these findings, the participants believed that the constructivist approach made the science and technology curriculum useful.

Opinions whether the Constructivist Approach is Effective in Teaching of Science and Technology Topics or not; In the research, the participants were asked whether the constructivist approach is effective in teaching of science and technology issues and the choices of the participants were shown in Figure 3.

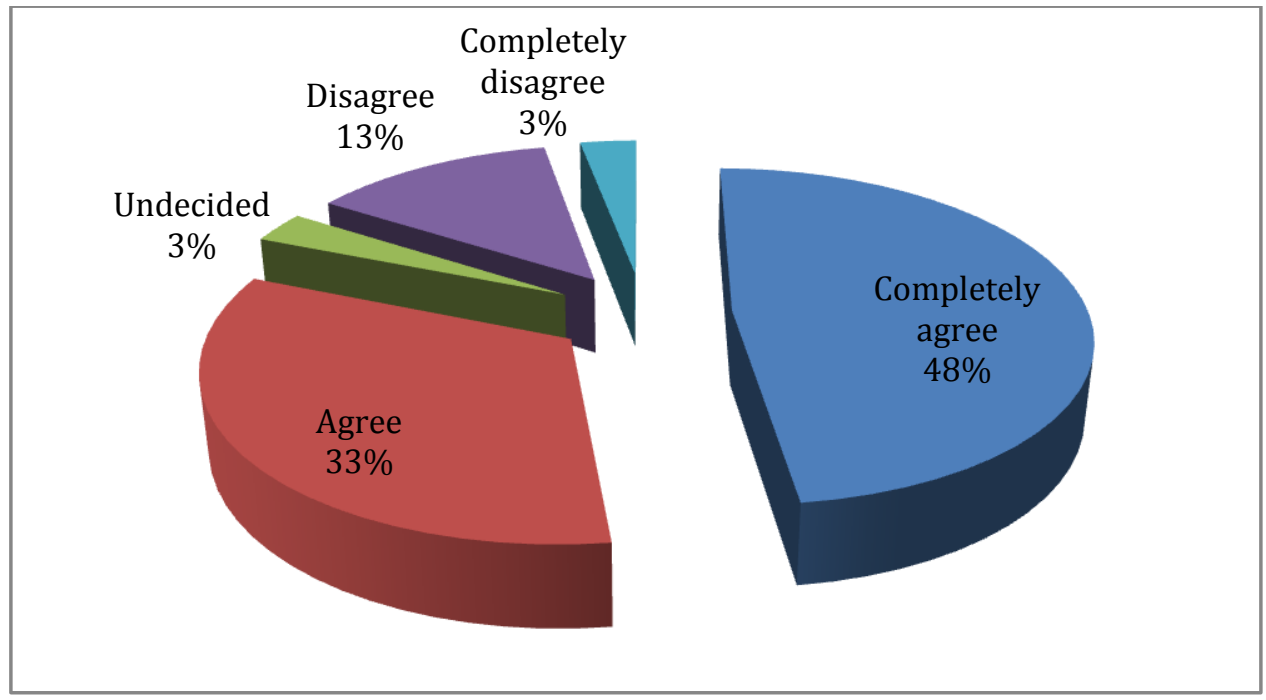

Figure 3.Opinions whether the constructivist approach is effective in teaching of science and technology topics or not

As the Figure 3 is investigated, it is noticed that $48 \%$ of the participants think that the constructivist approach is definitely effective in teaching the science and technology topics; on the other hand, $3 \%$ completely disagreed, $13 \%$ disagreed, $3 \%$ undecided, 33\% disagreed. Considering these findings, the participants are of the view that the constructivist approach is effective in teaching the science and technology topics.

Opinions of Science Teachers about Whether Making Interrelations between Lessons are Effective During Describing Topics in the Lessons; Whether making relations between lessons are effective during describing topics in the lessons in the research and the choice cases of the participants are indicated in Figure 4. 


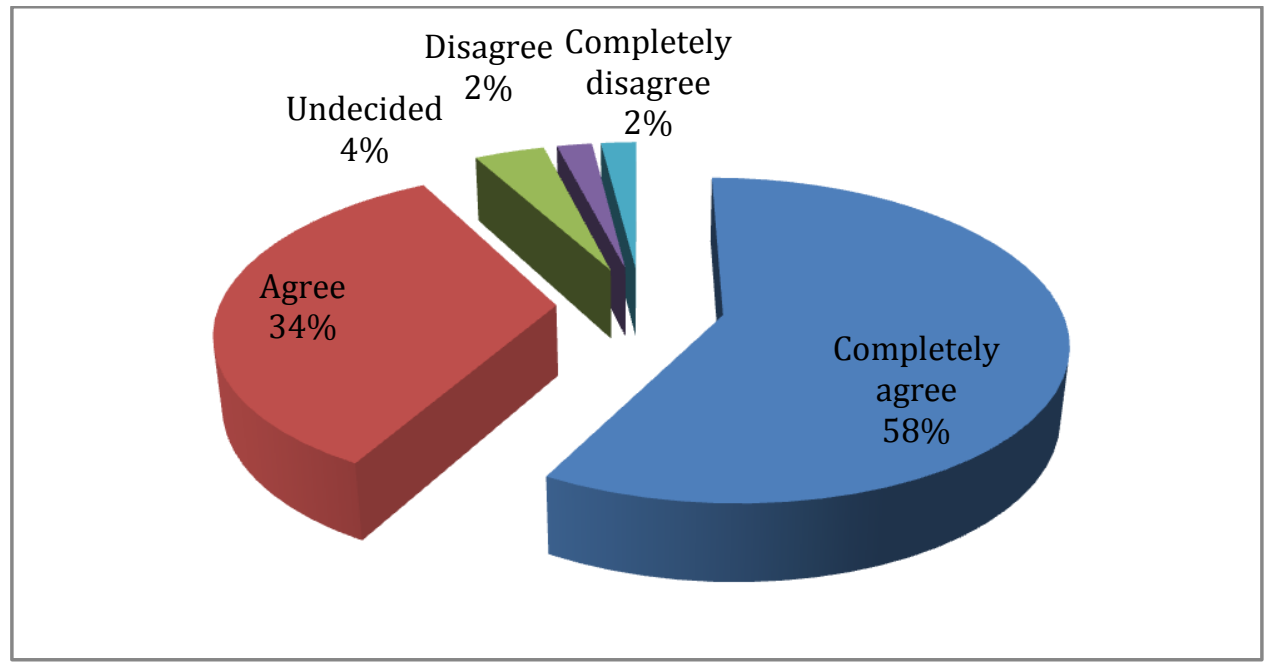

Figure 4.Opinions of the participants about whether making interrelations between lessons are effective during describing topics in the lessons.

As the Figure 4 is examined, 58\% of the participants included in the research thought that it was absolutely effective that science teachers' making interrelations between the lessons during describing the topics stated in the lesson; on the other hand, $2 \%$ of them completely disagree, $2 \%$ disagree, $4 \%$ undecided,34\% effective. Considering these findings, the participants are of the opinion that it is effective for science teachers to establish interrelations between the topics.

Opinions Related to Whether the Use of Contemporary Methods in In-class Evaluation is Useful or not;In the research, the participants were asked whether the use of contemporary methods in in-class evaluation is useful or not and the choice cases of the participants are shown in Figure 5.

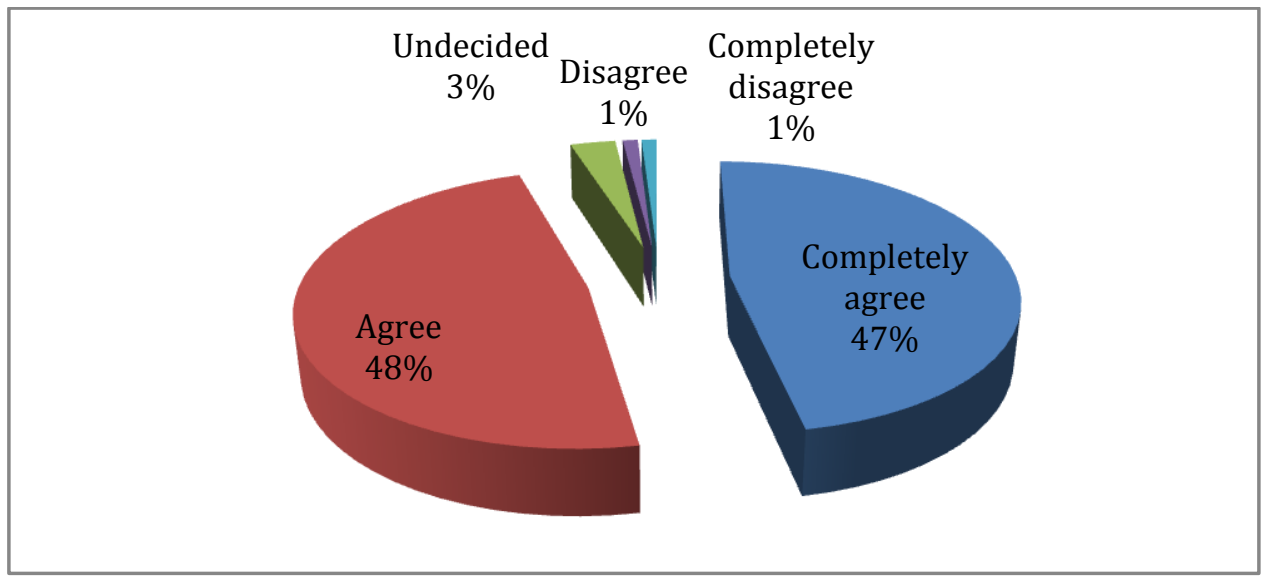

Figure 5.The participants' opinions related to whether the use of contemporary methods in in-class evaluation is useful or not

As the Figure 5 is examined, $47 \%$ of the participants included in the research thought that using the contemporary methods in in-class evaluation is not absolutely useful; on the other hand, $1 \%$ of them completely agreed, $1 \%$ agreed, $3 \%$ undecided, $48 \%$ thought that it was not useful. Considering these findings, the participants thought that using the contemporary methods in in-class evaluation is not useful.

Opinions about Whether There is a Relationship between EU Science Education Policies and Science Courses Taught in Turkey; In the research, the participants were asked whether there is a relationship between the EU science education policies and science courses taught in Turkey and the choice cases of the participants are presented in Figure 6. 


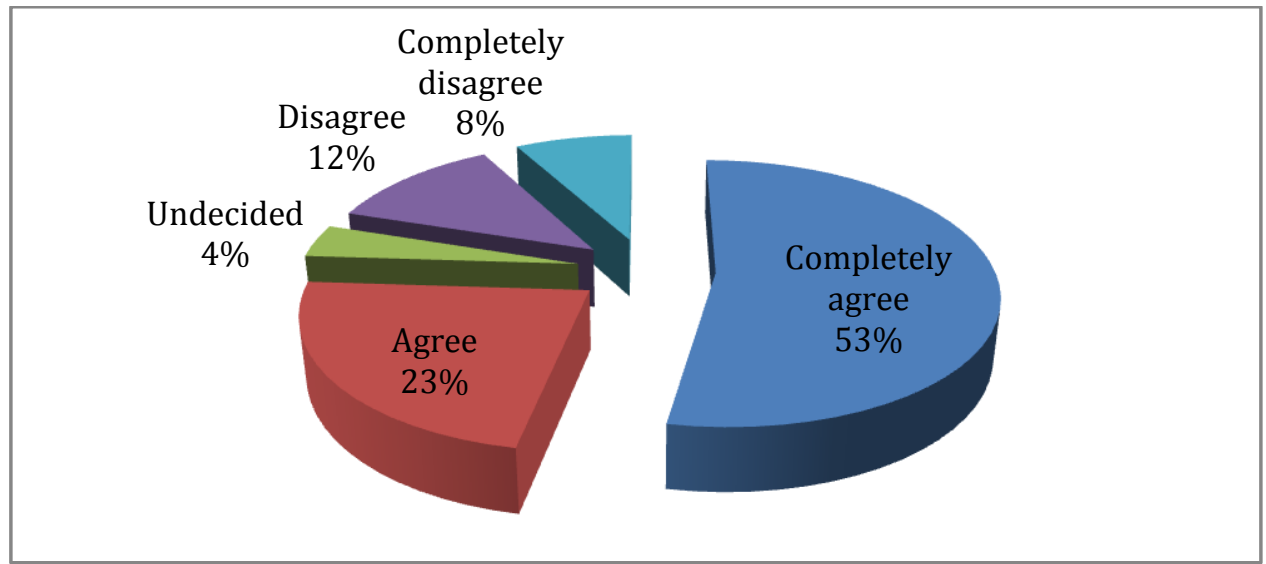

Figure 6. Opinions of the participants about whether there is a relationship between EU science education policies and science courses taught in Turkey

As the Figure 6 is analysed, it is found out that 53\% participants included in the research do not have any ideas related to whether there is a relationship between EU science education policies and science courses taught in Turkey, $12 \%$ do not agree, $8 \%$ thought that there was no relationship, $4 \%$ absolutely there was relationship, $23 \%$ there was relationship. Considering these findings, it can be claimed that the participants had no ideas about whether there is a relationship between EU science education policies and science courses taught in Turkey. Opinions about Whether the Curriculum was Prepared According to the Constructivist Approach or not; In the research, the participants were asked whether the curriculum was prepared according to the constructivist approach or not and their choices are shown in Figure 7.

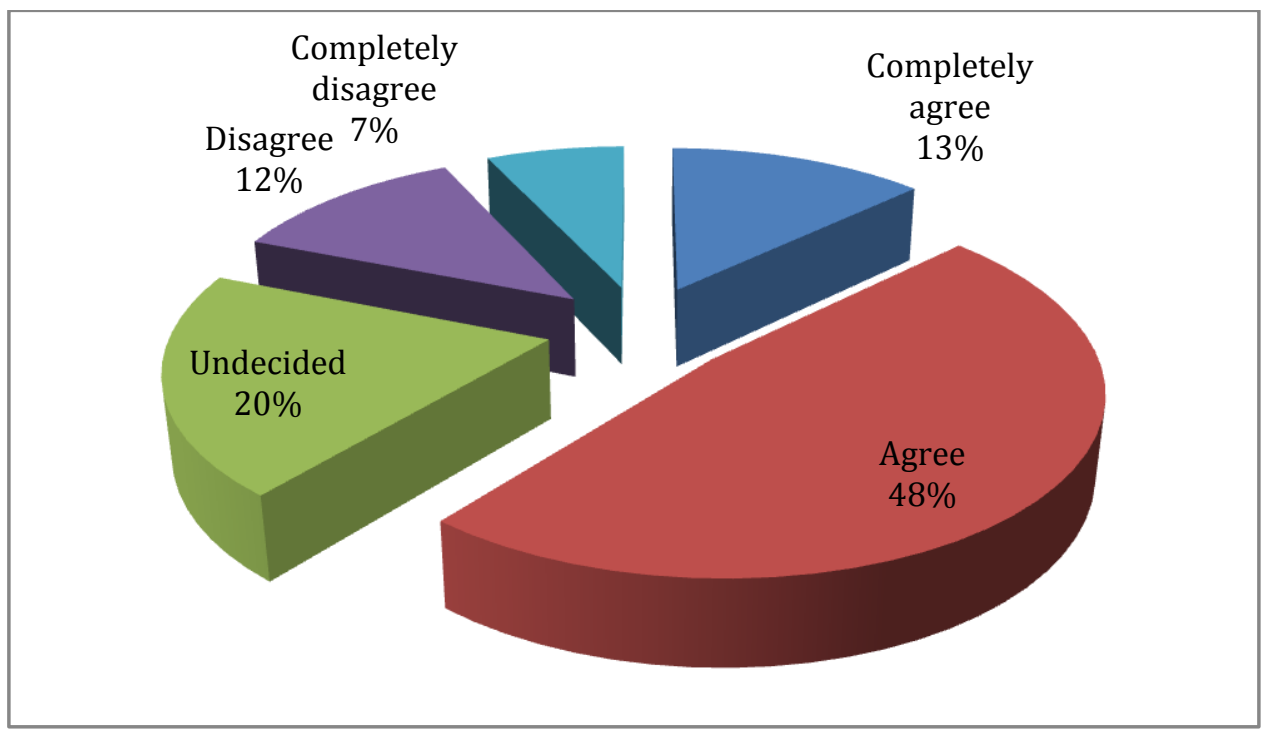

Figure 7.The opinions of the participants whether the curriculum was prepared according to the constructivist approach or not

As the Figure 7 is analysed, it is understood that $48 \%$ of the participants included in the research think that the curricula are prepared according to the constructivist approach, 13\% entirely agreed, $7 \%$ completely disagreed, $12 \%$ disagreed and $20 \%$ undecided. Considering these findings, it can be claimed that the participants think that the science curricula are prepared according to the constructivist approach.

Opinions Related to the Adequacy of In-Service Training to Improve Teacher Competencies; In the research, the participants were asked whether the in-service training to improve teacher competencies are adequate or not and the choices of the participants are shown in Figure 8. 


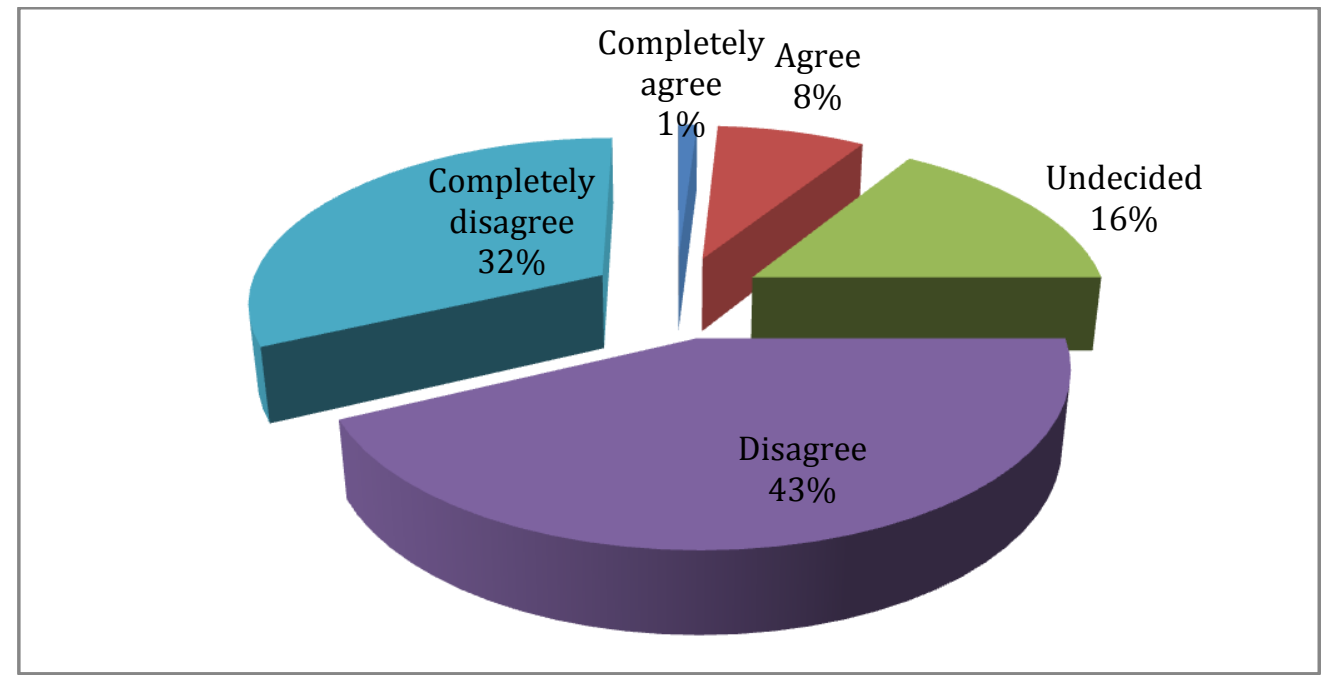

Figure 8.Opinions the participants related to the adequacy of in-service training to improve teacher competencies

As the Figure 8 is analysed, it is observed that while $32 \%$ of the participants included in the research think that the in-service training to improve teacher competencies is entirely insufficient, $1 \%$ completely agreed, $8 \%$ agreed, $16 \%$ undecided, $43 \%$ disagreed. Considering these findings, the participants think that the in-service training to improve the teacher competencies is not sufficient.

Opinions about Whether the Science Program is Related to More Real Life Experiences When Compared With the Previous Program; In the research, the participants' opinions were asked whether the science program is related to more real life experiences when compared with the previous program and the choice cases of the participants are shown in Figure 9.

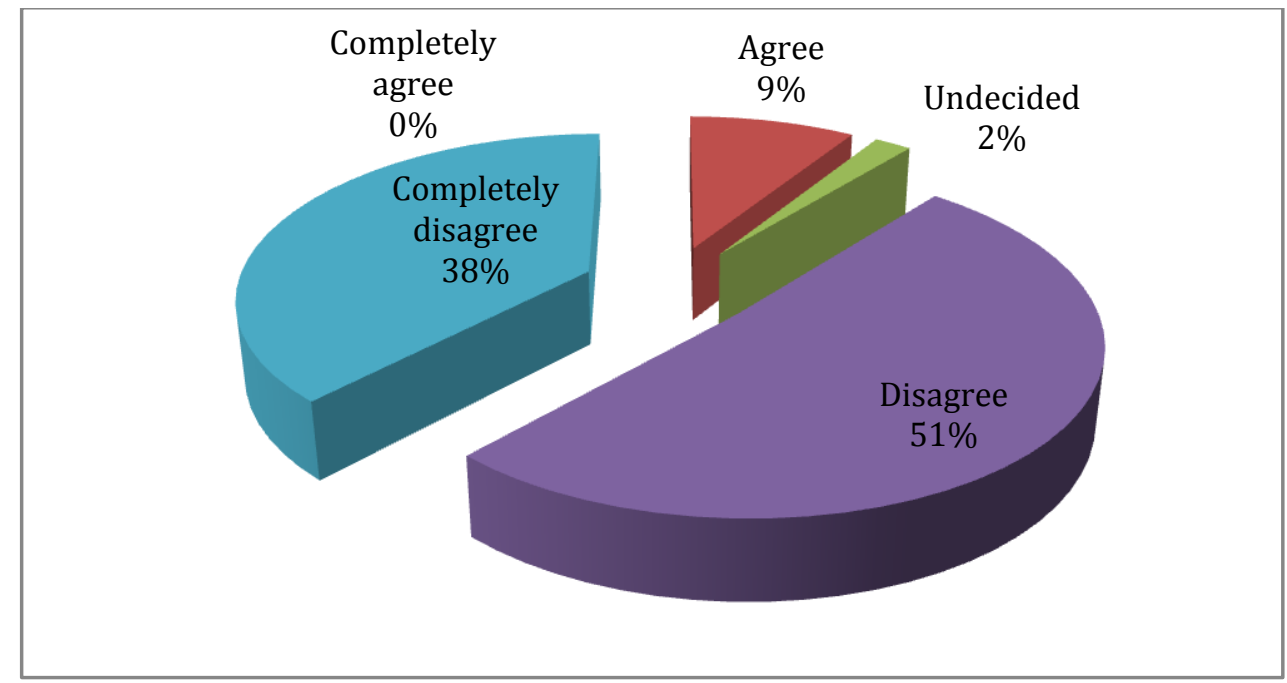

Figure 9 Opinions of the participants about whether the science program is related to more real life experiences when compared with the previous program

As the Figure 9 is analysed, it is observed that $38 \%$ of the participants included in the research think that is absolutely more relevant to the real life experiences when compared the science program with the previous one, 9\% disagreed, $2 \%$ undecided, $51 \%$ agreed. Considering these findings, the participants think that the science program is related to more real life experiences compared with the previous science program.

Opinions on Whether the Topics in New Science Program is Appropriate to Students' Levels or not; In the research, the participants were asked whether the topics stated in the new science program is appropriate to the students' levels or not and their choices are shown in Figure 10. 


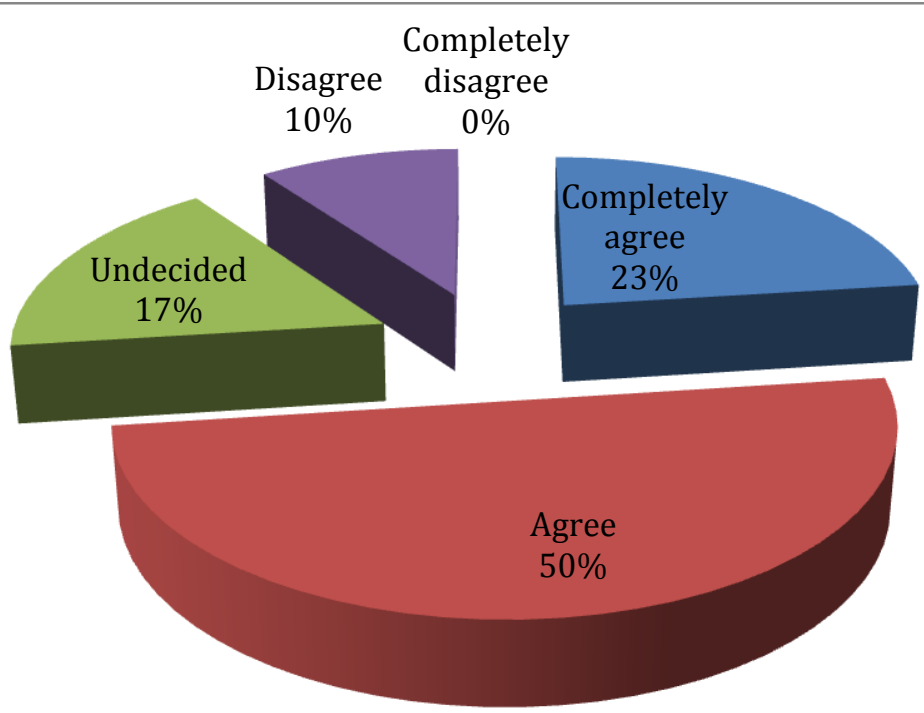

Figure 10. Opinions of the participants on whether the topic in new science program is appropriate to students' levels or not

As the Figure 10 is analysed, $23 \%$ of the participants included in the research think that the topics stated in the new science program are entirely appropriate to the students' levels, $10 \%$ disagreed, $50 \%$ agreed, $17 \%$ undecided, $50 \%$ agreed. Considering these findings, the participants think that the topics stated in the new science curriculum are appropriate to the students' levels.

The Participants' Views on EU Science Education Policies; The participants were asked, "What do you think about EU science education policies?"

In order to get their opinions about the EU science education policies qualitatively. From the answers given to these questions, three codes were handled as; in-service training, context-based learning and integrated education. Among the samplings, the M1 coded participant, related to the EU science education policies, stated in integrated education code saying; "Integrated education has already existed in our system for years, only it comes out with a different name as the spiral structure, pyramidal structure"'. In the sampling, the E1 coded participant stated in context-based learning claiming: "While making connections between courses makes the student be motivated; at the same time, it makes it easy to transfer what they learn to daily life".

Opinions of the Participants' Opinions about the Improvements in Science Courses in Turkey Considering EU Policies; In order to get the participants' views about the improvements in science lessons in Turkey considering the EU policies, they were asked "What do you think about the improvements in science lessons in Turkey considering the EU policies?" and their views were taken. The views of the participants about the improvements in science lessons were coded as; constructivist education, contemporary evaluation techniques, faculty of education.

About the improvements in science lessons in Turkey considering the EU policies, the M1 coded participant stated in the constructivist education code saying: "when we looked at the improvements, we observe that transferring to the new philosophy; that is, the constructivist approach is gradually being adopted compared with the previous program and some gains are reaching to the constructivist approach". The E1 coded participant from the sampling stated in the faculty of education code with the expression as: "while the ones who graduated from the high school were able to become a teacher, today the pre-service teacher who are educated with the package programs of the faculties of education are able to become teachers".

\section{Result}

This research was conducted to determine the views of the participants related to the improvements carried in science education in Turkey according to the EU science education policies. It was determined that most of the 
participants constituting the sampling were unaware of the EU policies according to the data gathered from the 12th sub-problem, and the findings gathered as a result of the research were statistically interpreted.

In addition, the data of the semi-structured protocols carried throughout the research process were analysed. The handled analysis results and interpretations were evaluated and the results and interpretations related to the each data collection tool were demonstrated appropriate to the sequence in the findings. The results gathered from various tools were evaluated in relation with each other and the research questions were tried to be answered in this way.

As a result of the findings in Figure 1 and the qualitative protocol results, the participants expressed their opinions as the active learning should be taken as the base while renewing the science curriculum, and the constructivist philosophy should be taken into consideration in the new curriculum. Related to this, $\ddot{\mathrm{O}}_{2}$ coded participant from the sampling pointed that some problems occurred because of the reasons encountered in application claiming: "the constructivist approach brought a new dimension to the science lesson. This philosophy taking the active learning as the base necessitates the students to be more active; on the other hand, highly populated classrooms make active learning difficult".

From the data stated in Figure 2, it can be claimed that the participants think that the constructivist approach makes the science and technology curriculum more useful. As a result of the qualitative protocols, the $\ddot{O}_{8}$ coded participant expressed that the constructivist approach made the science education more useful and its importance was not understood as a result saying: "teachers with years of experience do not know the constructivist approach, even if they know, they do not apply it; but young teachers know it. The constructivist approach made the science curriculum more useful compared with the previous one; but, it will be useful as long as it is applied. It has been used in our country since 2007; but, I think its importance is already being noticed teachers who noticed its importance are using it in their lessons".

As the graphical rates are taken into consideration in Figure 3, the participants claim that the constructivist approach is effective in teaching the topics stated in the science and technology lesson. As a result of the qualitative protocols, the $\mathrm{O}_{2}$ coded participant, related to this issue, took the importance that students will learn more effectively as long as the constructivist approach included students in lessons actively claiming: "as the constructivist approach takes the students to the centre of learning, it enables more active learning and this can be effective in teaching the lesson. Especially modernization of the laboratories, the experimental activities are being carried out more actively compared with the past. Nevertheless, because of the reasons as the struggle to give all the topics and the number of the acquisitions, some students cannot attend the learning actively".

Considering the findings in Figure 4, the participants claim that the science teachers setting relations between the lessons while they are teaching the topics are definitely effective. As a result of the qualitative protocols, the $\ddot{O}_{4}$ coded participant from the sampling took the attention to the associating the topics with other courses saying: "context-based teaching techniques are useful, because by the help of the associations between the lessons, and giving examples from daily life, students memorize the topics easily. In addition, as it is required an effective attendance, it forces the students to be active during the process".

The opinion of the participants that the use of contemporary methods in in-class evaluation is not beneficial is understood from the findings stated in Figure 5. As a result of the qualitative protocols, the Ö ${ }_{10}$ coded participant from the sampling claimed that the contemporary evaluation methods were useful saying: "I think the contemporary evaluation methods are useful. Because, we completely leave all the work to students and guide them; thus, we enable the students learn by doing and living. And this helps the individual learn more effectively". As a result of the findings stated in Figure 5 and other protocols, it can be concluded that most of the teachers are deficient in evaluation of the teaching process.

From the findings stated in Figure 6, it can be claimed that the participant have no idea about whether there is a relationship between the EU science education policies and the science lessons in Turkey. Among the sampling, the $\ddot{O}_{7}$ coded participant pointed that the system should be improved by expressing: "as I make evaluation by taking the policies into consideration, I think that the European countries are far from us. But now, we are reaching their levels gradually. We are trying to educate teachers as this way. We are arranging the course books according to their levels but we can go forward". 
From the graphical data in Figure 7, it can be claimed that the participants are in thought that the science curriculum are being arranged according to the constructivist method. With this question, the Ö${ }_{9}$ coded participant from the sampling pointed out that the curriculum is prepared according to the constructivist approach by claiming:

"both the curricula and the course books are including more activities compared with the past and by including more examples appropriate to the students' levels, they are prepared appropriate to the constructivist approach and they are still being prepared like this".

The findings in Figure 8 demonstrate that the participants think the in-service education to increase the teacher competencies is not sufficient. In the protocol conducted with the $\ddot{O}_{10}$ coded participant from the sampling, it is noticed that there are some problems generated from the practice understood from the words as: "teachers in the ministry of education perceive the in-service training as a trip. I don't this it is beneficial so. Therefore, it brings difficulty in terms of teachers. There are definite terms for the seminars. If they are conducted in those terms, it would be more effective. As most of these are conducted at the school-time, most teachers do not attend them. Most of the seminars I attended were like the trips. I have not encountered any benefits from them".

Considering the findings in Figure 9, the participants think that compared with the previous curriculum, the new science curriculum is more likely to include the real life experiences. Related to this question, the $\ddot{O}_{7}$ coded participant from the sampling concluded that the new science curriculum included more real-life experiences compared with the previous one saying: "the science curriculum consists of more contemporary knowledge compared with the previous one and create more awareness among the students towards the surrounding"

Considering the findings placed in Figure 10, the participants think that the topics in the new science curriculum are suitable for the levels of the students. Related to this question, the $\ddot{O}_{5}$ coded participant from the sampling claiming: "with the arrangements in the new science curriculum, the places of some of the topics were changed. For instance; the topic of simple machines omitted from the 7th grade and added in the 8th grade and arranged to be appropriate to students' level, stressed on that the topics stated in the new science curriculum are appropriate to the cognitive, behavioural and psycho-motor skills of the students.

In the qualitative protocols, among the similar protocols, theÖ ${ }_{10}$ coded participant defended that the science policies of the EU were positive and Turkey should be included in this structure by claiming: "The policies of EU are quite well. As they carry out scientific studies with several countries. It is extremely positive event for the countries to determine standards and conduct researches. Turkey should not be out of this. Absolutely, we have to participate in more". From this issue, the $\mathrm{O}_{8}$ coded participant from the sampling stressed to the point why Turkey cannot apply the policies totally by claiming: "The science education policies of the EU is similar to ours. The only difference is that we applied it after 2005. The reason why we applied it after 2005 is that there is no teacher educated according to this system. But as this system were applied in Europe long before, they are better than us" Considering the EU policies, related to the improvements in the science lessons in Turkey, the $\ddot{\mathrm{O}}_{2}$ coded participant stated in the code of constructivist education code by claiming: "when we look at the improvements, in passing to the new curriculum, we encounter with the new philosophy; that is the constructivist approach is admitted more compared with the previous curriculum. Especially, some gains we retransferred to the constructivist approach, which took my attention". Related to this question, the Ö$_{7}$ coded participant from the sampling claimed that improvements have been occurred in science lessons by claiming: "As a 12-year experienced teacher, I observed the process. There are some improvements in science lessons. That is; the topics were made simpler first. Secondly, the time of the lesson is raised to 4, it was 3 in a week. In addition, there is a lesson named: science practices. We carry out the activities, which we haven't carried because of the time limits. All these are the improvements and I believe that they are useful, too".

The qualitative and quantitative research results carried out with the participants constituting the sampling considering the EU science education policies were analysed, and it was found out that most of the participants constituting the sampling thought that we were back from the EU countries in terms of the science education, we could not catch up the EU science education policies especially in the field of education. It was understood from the results that most of the participants thought that the in-service training conducted to improve teacher competencies were insufficient and unbeneficial, were not used in terms of the benefits; so, did not contribute to the teachers during the teaching process. Within the lights of this result, it is believed that teachers should be educated in terms of their deficiencies in order to make the in-service training more useful and beneficial. 
Especially because of the crowded classes in, because of the worry by the central national examinations, doing test-oriented exams rather than the ones related to education, some problems such that the students cannot actively participate in teaching came into existence. When the sub-problems mentioned above are taken into consideration, it was observed that very few teachers were aware of the improvements carried in science education considering the EU education policies and these improvements were not included in practice.

\section{References}

Akpınar, B. (2006). AB’neuyumsürecindeTürkilköğretimöğrencilerinin AB imajı, Eğitimde Politika Analizlerive Stratejik Araştırmalar Dergisi, 1(1) 8-26.

Aslan, A.C., \&Gökkaya, K.A. (2004). Programe the politics of the education system ec applies to the general aims of social science lesson, Gazi University Journal of Gazi Educational Faculty, 24, (3) 227-244.

Balc1, A., (2013). Sosyalbilimlerdearaştırmayöntem, teknikveilkeler 10.Baskı, PegemAkademiYayın, Ankara, 103,132 .

Başbay, A., \&Doğan, N. (2004). Conceptions of Teachers Related to Effect of European Union Membership Adaptation Process on Our Education System, Ege Journal of Education, 5 ( 2) 35 -52

Cansever, A.B. (2009). Educational policies of European Union and evaluation of Turkey's adaptation process to these policies. International Online Journal of Educational Sciences, 1 (1), 222-232.

Cogan, J., \&McDevitt.J. (2003).Science, Technology and improvement policies in selected small European Countries.Helsinki, WATT, Valtiontaloudellinentutkimuskeskus, Goverment İnstitute for Economic Research, 2001, (B, ISSN 0788-5008, No 96).ISBN 951 -561- 444-9.

Demirbaş, F.İ. (2010). AB eğitimpolitikalarıveTürkiye.SelçukÜniversitesiSosyalBilimlerEnstitüsü, YüksekLisansTezi.

Eisfeld, R., \& Pal. A.L. (2010). Political science in central-east europe and the impact of politics: factors of diversity, forces of convergence. (223- 243) \& 2010 European Consortium for Political Research.16804333/10 www.palgrave-journals.com/eps.

Erginer, A. (2006). AB eğitimsistemleriveTürkiyeeğitimsistemiylekarşılaştırmalar.Pegem A Yayıncılık. ISBN: 9944-919-30-6, ANAKARA

Gedikoğlu, T. (2005). Turkish Education System in the Process of European Community: Problems and Solutions, Mersin University Journal of the Faculty of education, 1(1) 66-80.

Gültekin, M., \&Anagün, S.Ş. (2006). The condition of Turkish education system from the aspect of European Union's area and indicators determining the quality in education, Anadolu University Journal of Social Sciences 2, 145-170.

Hasdemir, F., \&Çalıkoğlu. R. M. (2011). The European Union education programmes and the change. Journal of Higher Education and Science, DOI: 10.5961/jhes.2011.010.

Karip, E. (2005). Globalization and Education 2010 Lisbon Objectives, 2, 195-209. https://www.pegem.net/dosyalar/dokuman/666-20110606105618-4-karip.pdf

Lewin, M.K. (2000). Mapping science education policy in developing countries.World Bank, Human development network, Secondary education series, Eric. 